\title{
In vitro effect of fluoride oral hygiene tablets on artificial caries lesion formation and remineralization in human enamel Peter Gängler ${ }^{\dagger}$, Thomas Kremniczky ${ }^{\dagger}$ and Wolfgang $\mathrm{H}$ Arnold*
}

Address: Faculty of Dental Medicine, University of Witten/Herdecke, Witten, Germany

Email: Peter Gängler - peter.gaengler@uni-wh.de; Thomas Kremniczky - tkremniczky@gmx.de; Wolfgang H Arnold* - wolfgang.arnold@uniwh.de

* Corresponding author †Equal contributors

Published: 2 October 2009

BMC Oral Health 2009, 9:25 doi:10.II86/|472-683|-9-25

Received: 27 April 2009

Accepted: 2 October 2009

This article is available from: http://www.biomedcentral.com//472-6831/9/25

(C) 2009 Gängler et al; licensee BioMed Central Ltd.

This is an Open Access article distributed under the terms of the Creative Commons Attribution License (http://creativecommons.org/licenses/by/2.0), which permits unrestricted use, distribution, and reproduction in any medium, provided the original work is properly cited.

\begin{abstract}
Background: Aim of this in-vitro-study was to assess the remineralization potential of a tooth cleaning tablet with different fluoride content.

Methods: Twenty three caries free impacted third molars were examined, enamel surfaces were wax coated leaving two $3 \times 4 \mathrm{~mm}$ windows for exposure to demineralization/remineralization cycles. The teeth were randomly assigned to 4 groups of 5 control and 6 experimental teeth. Demineralization by standardised HEC-gel, $\mathrm{pH} 4.7$ at $37^{\circ} \mathrm{C}$ for $72 \mathrm{~h}$, was alternated by rinsing in remineralization solution, $\mathrm{pH} 7.0$ at $37^{\circ} \mathrm{C}$ for $72 \mathrm{~h}$, total challenge time $432 \mathrm{~h}$. The negative control group $\mathrm{N}$ was treated during remineralization cycles with saline; positive control group $\mathrm{P}$ was treated with remineralization solution; experimental group $D I$ was exposed to remineralization solution containing Denttabs ${ }^{\circledR}$-tablets with $1450 \mathrm{ppm}$ F; experimental group D2 was exposed to remineralization solution and Denttabs ${ }^{\circledR}$-tablets with 4350 ppm F. Each tooth was cut into serial sections and analyzed by polarized light microscopy for assessment of the different zones of whitespot lesions in 3 representative sections. Statistical analysis was based on the Mann-Whitney-Test.
\end{abstract}

Results: Both control groups $\mathrm{N}(-)$ and $\mathrm{P}(+)$ exhibited characteristic white-spot lesions. The remineralization and the demineralization inhibition of the lesions increased considerably from $\mathrm{N}<\mathrm{P}<\mathrm{DI}<\mathrm{D} 2$. Denttabs ${ }^{\circledR}-2$ administration showed partial/total remineralization including lamination and/or disappearance of the body of the lesion. The different results of all 4 groups were statistically highly significant $(\mathrm{p}<0.0 \mathrm{I})$ with both tests.

Conclusion: Based on these results the novel Denttabs ${ }^{\circledR}$ formulation represents a highly effective oral hygiene product and the remineralization is correlated to the fluoride content.

\section{Background}

Fluoride dentifrices are widely used, and it is experimentally well established that they contribute to remineralization of incipient caries lesions in human and bovine enamel [1-3]. In the last decade many questions have been raised on the bioavailability of fluoride in oral fluids, and new formulations with different fluoride content are under investigation. Recently it has been demonstrated that elevated fluoride products enhance remineralization of advanced bovine enamel lesions [4]. 
On the other hand, the long or even life long presence of the human dentition combined with dietary influences and individual tooth brushing habits may lead to the risk of erosive and/or abrasive lesions of enamel and especially of root dentin. It was therefore the aim of the development of an oral hygiene agent in tablet form to increase the fluoride availability in oral fluids and to substitute the abrading effect of many traditional toothpastes by a polishing action due to microcrystalline hydroxyethyl cellulose. The resulting product (Denttabs ${ }^{\circledR}$, Prodentum, Berlin, Germany) is rapidly dissolved in saliva, and the fluoride bioavailability immediatedly after tooth brushing and 10 minutes after tooth brushing is higher (Median $165.2 \mathrm{ppm} \mathrm{F}$-) compared to a conventional dentifrice foam/saliva mixture (Median 123.7 ppm F-) (Naumova et al., Fluoride bioavailability in saliva after using DENT$\mathrm{TABS}^{\oplus}$ compared to dentifrice, submitted).

The oral hygiene tablets have also been clinically tested, and the plaque reducing efficiency was similar to a conventional dentifrice in a field study as well as in a controlled clinical trial [5].

The question remained whether an additional fluoride enhancement of remineralization could be expected for an elevated fluoride content of $4350 \mathrm{ppm}$ versus 1450 ppm in Denttabs ${ }^{\circledast}$. The higher fluoride concentration in $0.33 \mathrm{~g}$ tablets is equal to $1450 \mathrm{ppm} \mathrm{F}^{-}$per $1.00 \mathrm{~g}$ toothpaste as the common amount per application.

It was therefore the aim of this study to assess the relative efficiency of two fluoride treatments on demineralization and remineralization of human dental enamel in a $\mathrm{pH}$ cycling model. Qualitative and semi-quantitative polarized light microscopy of serial ground sections was used to detect the morphology of lesions and to assess the pore volume of de- and remineralization. Polarized light microscopy has been chosen as the method to determine the morphology of the different lesions because it allows distinguishing between the different lesion zones. Also the extent of the different lesions zones could be measured exactly.

\section{Methods \\ Tissue}

Twenty three completely impacted human third molars were used in agreement with GLP instructions governing the use of human tissue. These teeth were selected because of the uniform enamel structure with no individual challenges due to the non-exposure to the oral cavity. Immediately after clinically indicated surgical removal they were thoroughly cleaned of organic debris and stored in saline containing $0.1 \%$ thymol. No further surface treatment of the enamel was applied. The teeth were than coated with wax leaving a $3 \times 4 \mathrm{~mm}$ window on the buccal and lingual smooth surfaces and finally randomly assigned to 4 groups (Tab. 1).

\section{Demineralization/Remineralization, $\mathrm{pH}-\mathrm{Cycling}$}

$\mathrm{pH}$-cycling conditions were chosen to create advanced artificial enamel lesions on natural smooth surfaces. Each cycle was scheduled for 3 days and was repeated 6 times. The experimental period of $\mathrm{pH}$-cycling lasted therefore 18 days. After demineralization and remineralization (except for the negative control group) the specimens were rinsed in distilled water to remove excess treatment gel solution. Demineralization gel contained $1.5 \mathrm{mM} \mathrm{CaCl}_{2}, 0.9 \mathrm{mM}$ $\mathrm{KH}_{2} \mathrm{PO}_{4}, 150 \mathrm{mM} \mathrm{KCl}, 0.1 \mathrm{M}$ sodium acetate buffer, 30 $\mathrm{mM}$ acetate in hydroxyehtyl cellulose. The $\mathrm{pH}$ was adjusted to 4.7 and controlled before and after each 3 day cycle [6].

Remineralization solutions were comprised of $1.5 \mathrm{mM}$ $\mathrm{CaCl}_{2}, 0.9 \mathrm{mM} \mathrm{KH}_{2} \mathrm{PO}_{4}$, and $150 \mathrm{mM} \mathrm{KCl}$ at $\mathrm{pH}$ 7.0, again controlled before and after each 3 day cycle.

The wax coated teeth were fixed with metal wires and hang in the respective solutions (Figure 1) and the volume

Table I: Overall experimental design

\begin{tabular}{|c|c|c|c|c|}
\hline Group & Demineralisation & Remineralization & Teeth & Lesions \\
\hline $\begin{array}{c}\mathbf{N} \\
\text { (negative control) }\end{array}$ & $\begin{array}{c}\text { Standardized } \\
\text { HEC-gel } \\
\mathrm{pH} 4.7,37^{\circ} \mathrm{C}\end{array}$ & $\begin{array}{l}\text { Saline } \\
37^{\circ} \mathrm{C}\end{array}$ & 5 & 10 \\
\hline $\begin{array}{c}\mathbf{P} \\
\text { (positive control) }\end{array}$ & & $\begin{array}{l}\text { Remin. solution } \\
\mathrm{pH} 7.0,37^{\circ} \mathrm{C}\end{array}$ & 6 & 12 \\
\hline $\begin{array}{c}\text { DI } \\
\text { (experimental) }\end{array}$ & & $\begin{array}{c}\text { Remin. solution + Denttabs }{ }^{\circledR} \mid \mathbf{4 5 0} \mathrm{ppm} \text { F- } \\
\mathrm{pH} 7.0,37^{\circ} \mathrm{C}\end{array}$ & 6 & 12 \\
\hline $\begin{array}{c}\text { D2 } \\
\text { (experimental) }\end{array}$ & & $\begin{array}{c}\text { Remin. solution + Denttabs }{ }^{\circledR} 4350 \text { ppm F- } \\
\mathrm{pH} 7.0,37^{\circ} \mathrm{C}\end{array}$ & 6 & 12 \\
\hline
\end{tabular}




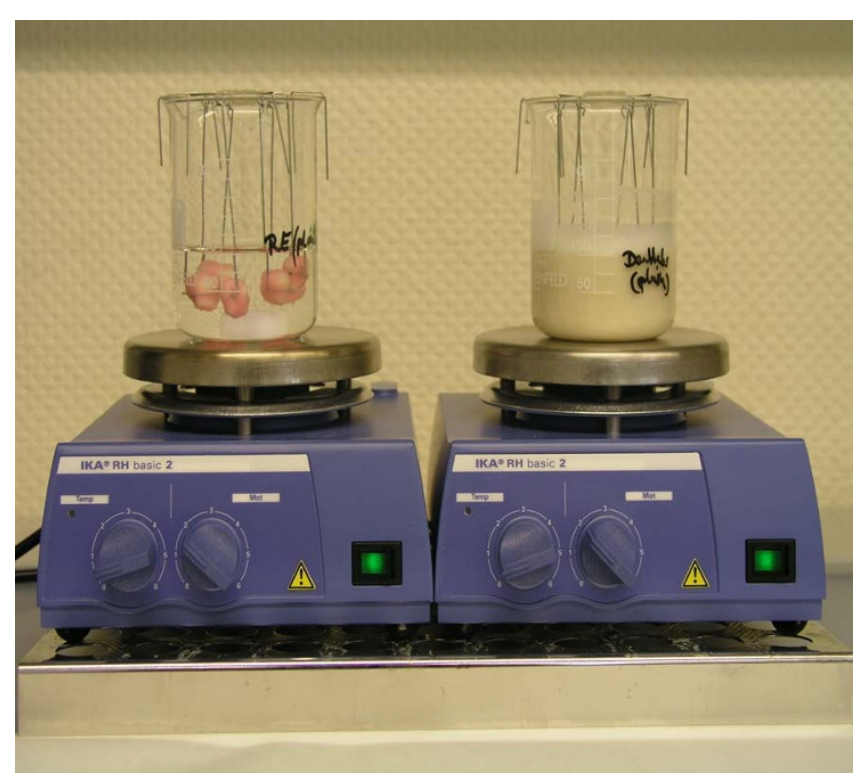

Figure I

Setup of the incubation procedure. The wax coated teeth were fixed to metal wires and were hanging in the different incubation media. The incubation media were constantly slowly agitated with a magnetic stirrer.

of each solution was $100 \mathrm{ml}$. These solutions were constantly agitated using a magnetic stirrer. All cycles were executed under constant climatic conditions at $37^{\circ}$. The window areas were microphotographically controlled before $\mathrm{pH}$-cycling to discard specimens with enamel cracks of iatrogenic scratches and to document the artificial white spot lesions after 18 days.

\section{Treatment groups}

The experimental scheme is presented in Table 1 . The negative control group $\mathrm{N}$ of 5 teeth with 10 lesions underwent demineralization cycles only and was kept during the remineralization cycles in saline. The positive control group P of 6 teeth with 12 lesions was remineralized in the specified solution without fluoride content. The 2 experimental groups (D1 and D2) of 6 teeth with 12 lesions each were exposed to remineralization solution containing Denttabs ${ }^{\oplus}$ with 1450 ppm F- (D1) or Denttabs ${ }^{\oplus}$ with 4350 ppm F- (D2). The oral hygiene tablets contain fluoride from $\mathrm{NaF}$, and the other ingredients according to INCI are microcrystalline hydroxyethyl cellulose, hydrated silica, sodium hydrogen carbonate, sodium laurylsulfate, ascorbic acid, magnesium stearate, aspartame and mint flavor.

The tablets were suspended in the remineralization solution with a ratio of one tablet per $5 \mathrm{ml}$ solution to simulate the maximal bioavailability of fluoride immediately after brushing (Naumova et al., Fluoride bioavailability in saliva after using DENTTABS ${ }^{\circledast}$ compared to dentifrice, submitted).

\section{Polarized light microscopy (PLM)}

After removal of the wax coatings standardized micro photos of all lesions at $10 \times$ magnification were taken. Before further processing the roots were removed. All teeth were then dehydrated in graded alcohol and embedded in Technovit 9100 (Kulzer, Weinheim, Germany). Serial ground sections were cut with a saw microtome (LEICA CM 1900, Leica, Wetzlar, Germany) with a thickness of $80 \mu \mathrm{m}$ in corono-apical direction. Three ground sections per tooth representing two approximal and one middle area of the lesions were used for qualitative and semi quantitative assessment of the lesion morphology.

The qualitative assessment of lesion zone characteristics included the homogeneity of the superficial zone and of the body of the lesion representing the area-specific mineral loss due to changing birefringence of different pore volumes imbibited with Technovit 9100. In addition the presence of laminations in the body of the lesion and the detectable translucent zone was analyzed.

For quantitative analysis the extent of the respective caries-like lesion zones (surface zone, body of the lesion, translucent zone) was measured in $\mu \mathrm{m}$ integrating their maximal and minimal values and continuing in equal distances over the whole lesion until 10 measurements were assessed. Three sections of each lesion were selected for the measurements.

\section{Statistics}

Because the data showed no normal distribution statistical analysis was done using the non parametric MannWhitney U test and SPSS 14 as computer program. Significance was determined at $\mathrm{p}<0.05$.

\section{Results}

\section{Macroscopic appearance}

In all 4 groups after 18 experimental days artificial carieslike enamel lesions of different intensity were detected. None of these lesions exhibited surface erosion, and the surface morphology at $10 \times$ magnification was similar to sound enamel around the lesions. However, there was a marked difference of the appearance of subsurface whitespot lesions. The negative control group $\mathrm{N}$ showed rather homogeneous advanced white-spot lesions, whereas in the positive control group $\mathrm{P}$ the white spot lesions were less homogeneous with color changes. In contrast both experimental groups D1 and D2 resulted in less intensive white-spot lesions, and the least subsurface demineralization close to non detectable white spots was documented for D2 (Figure 2). 


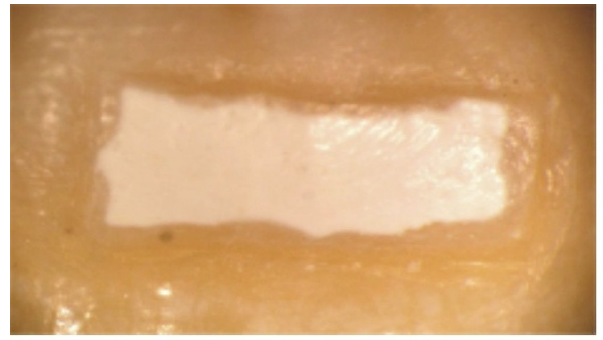

a

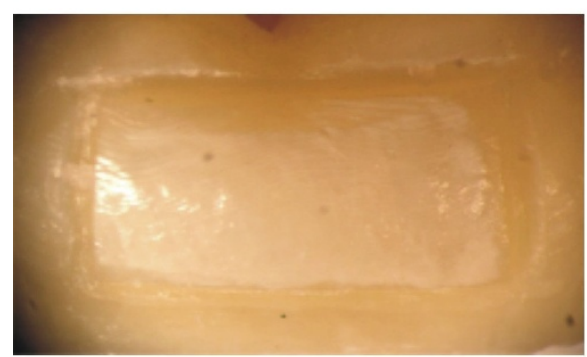

C

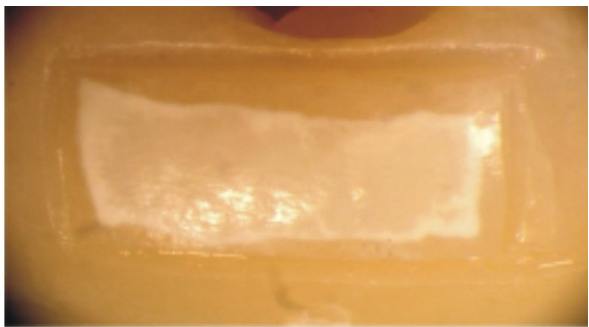

b

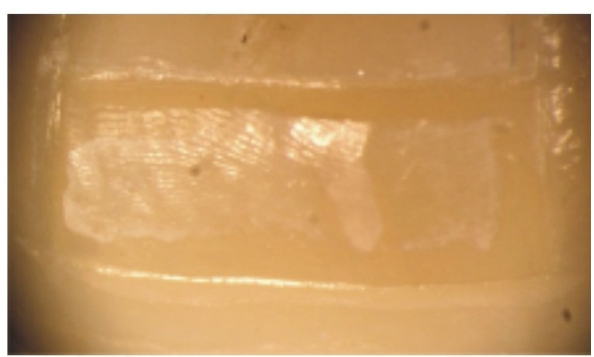

d

Figure 2

Appearance of the experimental lesions. White-spot lesions in the control group $N(a)$, remineralization group $P$ (b), experimental group DI with Denttabs ${ }^{\circledR} \mid 450$ ppm fluoride (c) and experimental group D2 with Denttabs ${ }^{\circledR} 4350$ ppm fluoride (d).

\section{Qualitative PLM assessment}

The characteristic features of 3 ground sections per lesion are summarized in Table 2 . The surface zone and the body of the lesion in experimental D1 and D2 groups were less homogenous because of the lower pore volume. Laminations within the body of the lesions were predominantly detected in experimental groups D1 and D2. D2 group showed partial or total remineralization including lamination and/or disappearance of the body of the lesion (Figure 3).

\section{Quantitative PLM assessment}

The results of all measurements of the extent of the surface zone, the body of the lesion, and of the translucent zone are presented in Table 3. The surface zone of group $\mathrm{N}$ was significantly more extended compared to all other groups $(\mathrm{p}<0.01)$. The differences in the extent of the body of the lesion were highly significant showing the least demineralization for group D2 with high fluoride content ( $\mathrm{p}<$ $0.001)$. The extent of mineral loss per lesion and per group was $\mathrm{N}>\mathrm{P}>\mathrm{D} 1>\mathrm{D} 2$. The translucent zone was more extended in group D2 and statistically highly different from all other groups $(\mathrm{p}<0.001)$. This was confirmed by the Kruskal - Wallis test $(\mathrm{p}<0.001)$. The results were the same for the overall depth of all lesion zones as well as for the minimal and maximal extent. The most mineral loss was observed in the negative control group $\mathrm{N}$, and the least loss in the fluoride group D2 $(\mathrm{N}>\mathrm{P}>\mathrm{D} 1>\mathrm{D} 2)$.

\section{Discussion}

Previous studies of the natural history of human enamel caries lesions in deciduous and permanent teeth using

Table 2: Qualitative polarized light microscopy with characteristic features of artificial enamel lesions, percentage of serial ground sections

\begin{tabular}{lllll}
\hline Group & Surface zone homogeneous & $\begin{array}{l}\text { Body of the lesion } \\
\text { homogeneous }\end{array}$ & Presence of laminations & Detection of translucent zone \\
\hline N & $100 \%$ & $90.0 \%$ & $85.0 \%$ \\
\hline P & $100 \%$ & $87.5 \%$ & $8.3 \%$ & $95.8 \%$ \\
\hline D1 & $83.3 \%$ & $75.0 \%$ & $37.0 \%$ & $100 \%$ \\
\hline D2 & $\mathbf{7 0 . 8} \%$ & $\mathbf{6 2 . 5 \%}$ & $\mathbf{4 5 . 8 \%}$ & $100 \%$ \\
\hline
\end{tabular}




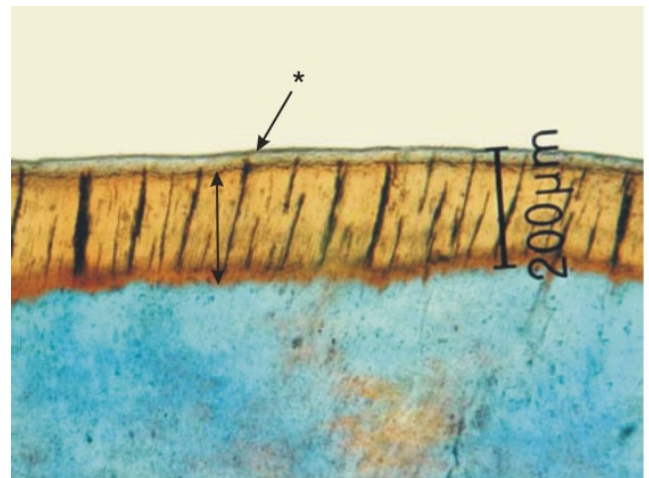

a

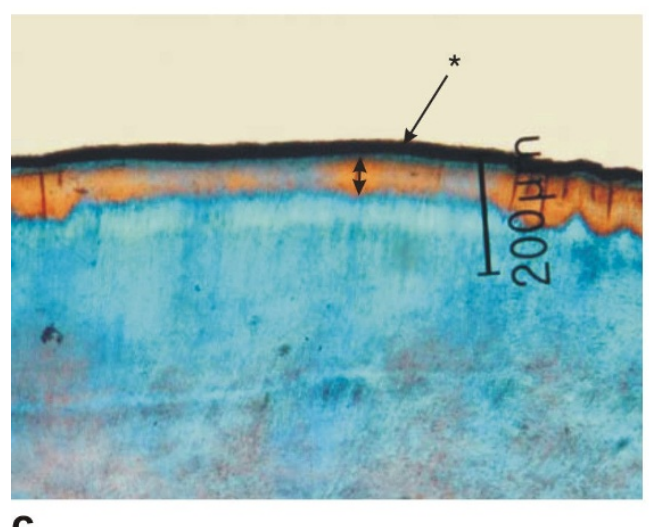

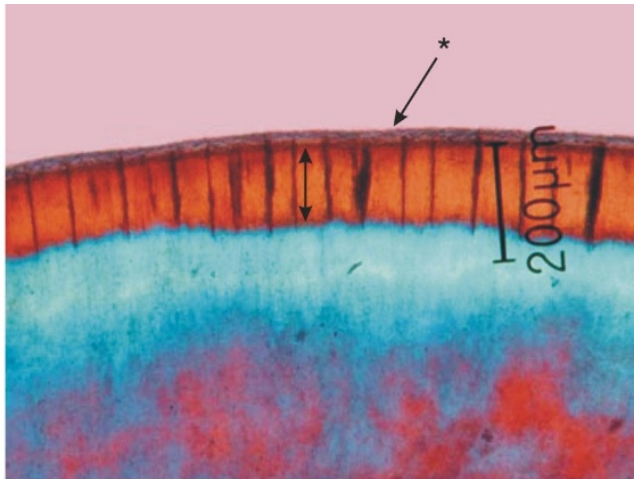

b

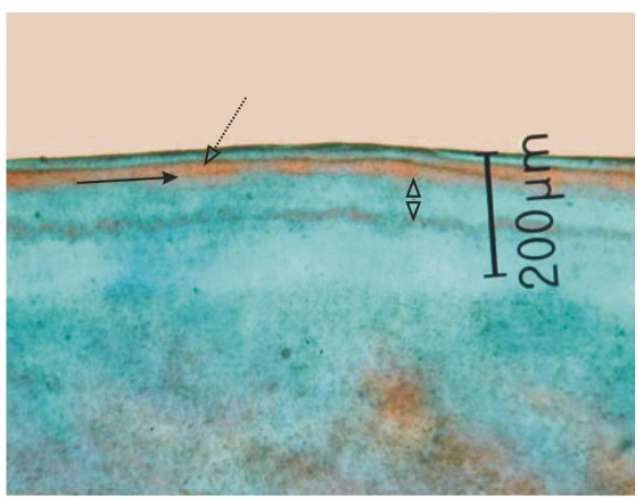

d

Figure 3

Polarized light micrographs of morphological examples of the 4 groups of control and experimental teeth. a) Negative control N: Homogeneous surface zone, demineralized body of the lesion with no laminations; arrow with asterisk = surface zone, double arrow = body of the lesion. b) Positive control P: Homogeneous surface zone, smaller body of the lesion, detectable translucent zone; arrow with asterisk = surface zone, double arrow = body of the lesion. c) Experimental group D I: homogeneous surface zone, small band of the body of the lesion, detectable translucent zone arrow with asterisk $=$ surface zone, double arrow = body of the lesion. d) Experimental group D2: Homogeneous surface zone, disappearing body of the lesion with laminations, broad translucent zone; dotted line with outlined arrow = laminated body of the lesion, arrow = laminations; double outlines arrow = translucent zone.

Table 3: Extent of lesion zones in $\mu \mathrm{m}$ in the different groups

\begin{tabular}{lcccccccccc}
\hline & \multicolumn{3}{c}{ Surface zone } & \multicolumn{3}{c}{ Body of lesion } & & \multicolumn{2}{c}{ Translucent zone } \\
\hline Group & Median & Mean & STD & Median & Mean & STD & Median & Mean & STD \\
\hline N & 14,2 & 15,7 & 5,5 & 203,5 & 203,3 & 40,7 & 67,8 & 78,9 & 30,9 \\
\hline P & 10,7 & 10,9 & 2,9 & 135,7 & 132 & 20,3 & 89,2 & 87,6 & 18,6 \\
\hline DI & 10,7 & 10,5 & 3 & 71,4 & 72 & 13,1 & 75 & 79,3 & 22,6 \\
\hline D2 & 10,7 & 11,2 & 5,5 & 35,7 & 37,2 & 13 & 100 & 99,4 & 36,7 \\
\hline
\end{tabular}


three dimensional features of polarized light microscopy have contributed to the understanding of the dynamics of caries progression [7-9]. The same methodology including the 3D-reconstruction of artificial caries-like lesions and the assessment of the volume of the body of the lesion has been exploited for testing various toothpastes [1] and under different pH conditions [10]. The size, volume and configuration of these artificial lesions differ greatly from the typical characteristics of natural early onset, arrested or progressing lesions. However, the lesion zones in polarized light according to Gustafson [11] are the same, and artificially created caries-like lesions are widely used to detect the regulation of mineral deposition and dissolution [3] and to determine the relative efficiency of fluoride toothpastes under $\mathrm{pH}$ cycling conditions [2].

The data of the present study confirm the effects of fluoride on demineralization and remineralization of human enamel. It was found that the demineralization regime over 18 days created advanced caries-like lesions with homogeneous surface zones and high pore volumes of the body of the lesion. The extent was around $200 \mu \mathrm{m}$ and different from the positive control teeth in $\mathrm{pH}$ cycling with standard remineralization solution with a depth around $120 \mu \mathrm{m}$.

The fluoride availability from $1450 \mathrm{ppm}$ containing oral hygiene tablets in the remineralization solution was equal to $96 \mathrm{ppm}$ (one $0.33 \mathrm{~g}$ tablet per $5 \mathrm{ml}$ solution) what corresponds to the fluoride bioavailability from a conventional $1400 \mathrm{ppm}$ F- dentifrice in saliva immediately after tooth brushing (Naumova et al., Fluoride bioavailability in saliva after using DENTTABS ${ }^{\varpi}$ compared to dentifrice, submitted). The elevated fluoride availability from the $4350 \mathrm{ppm}$ containing oral hygiene tablets was $287 \mathrm{ppm}$ what again simulates the bioavailability in saliva after tooth brushing with Denttabs ${ }^{\circledast}$.

In both experimental groups of teeth the mineral loss decreased tremendously and the different extent of the body of the lesion was highly significant. The lesion depth of the conventional fluoride group D1 was around $70 \mu \mathrm{m}$, and the body of the lesion in the elevated fluoride group $\mathrm{D} 2$ was even smaller around $40 \mu \mathrm{m}$. The translucent zone did not differ in control groups and in the conventional fluoride group D1. However, this zone of demineralizing front was significantly more extended in the elevated fluoride group D2 representing mainly inhibition of demineralization in the inner part of the lesion in contrast to mineral uptake in the outer part of the human enamel lesion. There was also a sharp increase of laminations in close to half of all sections. In contrast, laminations were very rare in the remineralization group with no fluoride, and they were completely absent in the teeth with dem- ineralization cycles only. In natural white-spot lesions laminations are attributed to short or long-lasting periods of different caries challenge $[12,13]$. Ten Cate et al. [2] showed that mineral uptake and loss occur at different depths within the lesions, and they assumed that fluorideinduced recrystallization has made the crystallites larger and less soluble in acid. Our PLM features confirm this hypothesis, and they demonstrate a clear dose response. The marked difference in the mineral structure of artificial incipient lesions, compared to that of sound enamel, gives rise to the phenomenon of simultaneous remineralization and demineralization. Quantitative microradiographic studies after application of higher fluoride concentration showed an increase in remineralization in the outer lesion and a decrease in demineralization in the inner part, resulting in a significant increase in mineral gain [3]. It has recently been discussed that with elevated external F- levels, the F- gradient might be higher, driving the fluoride deeper into the advanced lesion, in spite of the F- diffusion being slowed by adsorption onto and reaction with hydroxyapatite crystallites [4]. According to these results higher concentrations of fluoride are required to prevent the progression of artificial caries-like lesions. Therefore, the F-bioavailability in oral fluids simulated by the presented study design plays a significant role in enhancing remineralization of enamel caries lesions.

\section{Conclusion}

In conclusion, remineralization and demineralization of advanced human enamel caries-like lesions were found to benefit from higher fluoride concentrations (4350 ppm versus $1450 \mathrm{ppm}$ ) during oral hygiene tablet treatment in a pH cycling model.

\section{Competing interests}

The authors declare that they have no competing interests. Prodentum, Berlin, Germany provided the DETTABS ${ }^{\circledast}$ for this investigation but had no further influence on the study design.

\section{Authors' contributions}

PG was responsible for writing the manuscript. TK carried out the experiments and the measurements. WHA was responsible for the morphological studies.

All authors read and approved the final version of the manuscript.

\section{Acknowledgements}

The authors thank Mrs. Susanne Haussmann for her technical assistance.

\section{References}

I. Arnold WH, Dorow A, Langenhorst S, Gintner Z, Banoczy J, Gaengler P: Effect of fluoride toothpastes on enamel demineralization. BMC Oral Health 2006, 6:8. 
2. ten Cate JM, Exterkate RA, Buijs MJ: The relative efficacy of fluoride toothpastes assessed with pH cycling. Caries Res 2006, 40(2): |36-|4|.

3. Yamazaki H, Litman A, Margolis HC: Effect of fluoride on artificial caries lesion progression and repair in human enamel: regulation of mineral deposition and dissolution under in vivo-like conditions. Arch Oral Biol 2007, 52(2): I I0-I20.

4. ten Cate JM, Buijs MJ, Miller CC, Exterkate RA: Elevated fluoride products enhance remineralization of advanced enamel lesions. J Dent Res 2008, 87( 10 ):943-947.

5. Böshagen C, Eifler H, Gängler P: Klinische Bewertung der Mundhygieneeffektivität einer Zahnputztablette. Zahnarzt und Praxis 2005, 8:420-424.

6. Gangler P, Noren JG, Hoyer I, Bjarnason S, Kraft U, Odelius H, Wucherpfennig G: Reactivity of young and old human enamel to demineralization. Scand J Dent Res 1993, I0 (6):345-349.

7. Arnold WH, Gaengler P, Sabov K, Schmitz I, Gedalia I, Steinberg D: Induction and 3D reconstruction of caries-like lesions in an experimental dental plaque biofilm model. J Oral Rehabil 200I, 28(8):748-754.

8. Arnold WH, Gaengler P, Saeuberlich E: Distribution and volumetric assessment of initial approximal caries lesions in human premolars and permanent molars using computer-aided three-dimensional reconstruction. Arch Oral Biol 2000, 45(I2): 1065-107I.

9. Arnold WH, Konopka S, Kriwalsky MS, Gaengler P: Morphological analysis and chemical content of natural dentin carious lesion zones. Ann Anat 2003, 185(5):419-424.

10. Arnold WH, Haase A, Hacklaender J, Gintner Z, Banoczy J, Gaengler $\mathrm{P}$ : Effect of $\mathrm{pH}$ of amine fluoride containing toothpastes on enamel remineralization in vitro. BMC Oral Health 2007, 7:14.

II. Gustafson G: The histopathology of caries of human dental enamel with special reference to the division of the lesion into zones. Acta Odontol Scand 1957, 15:13-55.

12. Arnold WH, Cerman M, Neuhaus K, Gaengler P: Volumetric assessment and quantitative element analysis of the effect of fluoridated milk on enamel demineralization. Arch Oral Biol 2003, 48(6): 467-473.

13. Driessens FC, Theuns HM, Heijligers HJ, Borggreven JM: Microradiography and electron microprobe analysis of some natural white and brown spot enamel lesions with and without laminations. Caries Res 1986, 20(5):398-405.

\section{Pre-publication history}

The pre-publication history for this paper can be accessed here:

http://www.biomedcentral.com/1472-6831/9/25/prepub http.//www.biomedcentral.com/1472-6831/9/25 